\title{
Salvage Therapy for Childhood Medulloblastoma: A Single Center Experience
}

\author{
Michelle M. Kameda-Smith, Alick Wang, Noora Abdulhadi, Rebecca Voth, Anjali \\ Sergeant, Arjuna Maharaj, David Bakhshinyan, Ashley A. Adile, Akshat M. Pai, \\ Olufemi Ajani, Blake Yarascavitch, M. Cheryl Alyman, JoAnn Duckworth, M. \\ Constantine Samaan, Forough Farrokhyar, Sheila K. Singh, Adam Fleming on \\ behalf of the Pediatric Brain Tumour Study Group
}

\begin{abstract}
Introduction: Children diagnosed with medulloblastoma (MB) who are refractory to upfront therapy or experience recurrence have very poor prognoses. Although phase I and phase II trials exist, these treatments bear significant treatment-related morbidity and mortality. Methods: A retrospective review of children diagnosed with a recurrence of MB from 2002 to 2015 at McMaster University was undertaken. Results: Recurrent disease in 10 patients involved leptomeningeal dissemination, with 3 experiencing local recurrence. In three recurrent patients the disease significantly progressed, and the children were palliated. The remaining 10 children underwent some form of salvage therapy, including surgical re-resection, radiation, and chemotherapy, either in isolation or in varying combinations. Of the 13 children experiencing treatment-refractory or recurrent disease, 4 are currently alive with a median follow-up of 38.5 months (75.5 months). Of the eight patients with molecular subgrouping data, none of the Wnt MB experienced recurrence. Conclusion: Recurrent MB carried a poor prognosis with a 5-year overall survival (OS) of $18.2 \%$ despite the administration of salvage therapy. The upfront therapy received, available treatment, and tolerability of the proposed salvage therapy resulted in significant heterogeneity in the treatment of our recurrent cohort.
\end{abstract}

RÉSUMÉ: Traitement de sauvetage dans le cas du médulloblastome chez l'enfant : une expérience menée au sein d'un établissement hospitalier. Introduction: Les enfants chez qui l'on a diagnostiqué un médulloblastome réfractaire à un traitement initial ou qui sont victimes d'une récidive présentent d'habitude des pronostics de guérison vraiment défavorables. Bien qu'il existe des traitements basés sur des essais cliniques de phases I et II, ces traitements ont tendance à produire des taux notables de morbidité et de mortalité. Méthodes: Nous avons ainsi mené à l'Université McMaster une analyse rétrospective des dossiers d'enfants chez qui l'on avait diagnostiqué entre 2002 et 2015 une récidive de médulloblastome. Résultats: La réapparition de cette maladie chez 10 patients a provoqué un phénomène de diffusion leptoméningée, trois d'entre eux étant victimes d'une récidive locale. Sur ces 10 jeunes patients, la maladie a progressé de façon importante : ces enfants ont alors été transférés aux soins palliatifs. Quant aux autres 10 enfants, ils ont subi un certain type de traitement de sauvetage (des résections chirurgicales, de la radiothérapie, de la chimiothérapie), que ce soit de façon exclusive ou en variant les combinaisons possibles. Sur les 13 enfants réfractaires à un traitement initial ou victimes d'une récidive, 4 sont toujours en vie, leur suivi médian ayant été de 38,5 mois (75,5 mois). Sur les 8 patients pour qui on a pu obtenir des données moléculaires, aucun de ceux qui étaient atteints d'un médulloblastome du sous-type Wnt n'a connu de récidive. Conclusion: Les médulloblastomes qui réapparaissent après une période de guérison complète présentent un pronostic de guérison défavorable. Leur taux de survie globale est en effet de 18,2 \% au cours d'une période de 5 ans, et ce, même après avoir bénéficié d'un traitement de sauvetage. Ajoutons aussi que le type de traitement initial reçu, la disponibilité des traitements ainsi que la tolérance à l'égard des traitements de sauvetage proposés a entraîné une grande hétérogénéité dans le traitement de ces jeunes patients victimes d'une récidive.

Keywords: Recurrent or treatment-refractory pediatric medulloblastoma, Salvage therapy

doi:10.1017/cjn.2019.39

Can J Neurol Sci. 2019; 46: 403-414

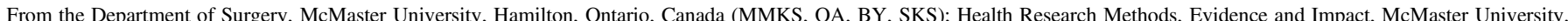

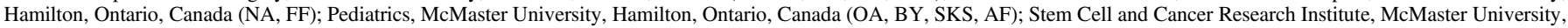

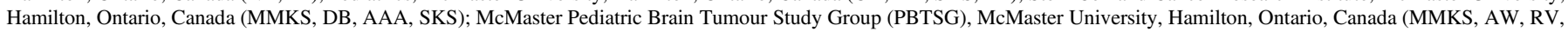
AS, AM, AMP, OA, BY, MCA, JD, MCS, FF, SKS, AF)

Received August 11, 2018. Final Revisions Submitted March 3, 2019. Date of Acceptance March 25, 2019.

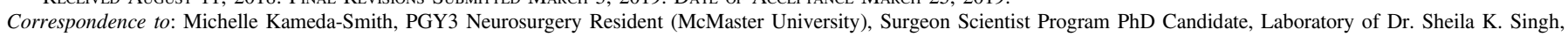
Medulloblastoma Stem Cell Research Program, McMaster SCC-RI, MDCL 5061, 1280 Main St. W., Hamilton, ON, Canada, L8S 4K1. Email: michelle.kameda@medportal.ca

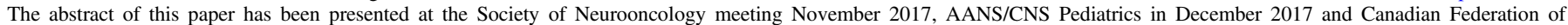
Neurological Sciences (CNSF) in June 2018. 


\section{INTRODUCTION}

The most effective salvage therapy in pediatric-refractory or relapsed brain tumors is yet to be established. ${ }^{1}$ The contemporary approach to upfront therapy for primary pediatric medulloblastoma (MB) is dependent on the patient's age, size of post-operative residual tumor, and evidence of metastasis at diagnosis. ${ }^{2}$ This clinical risk stratification strategy for pediatric MB allocates children into either standard or high-risk groups, where the latter group of children will receive higher doses of upfront radiation. High-risk disease is characterized by the presence of children of age less than 3 years, the presence of metastasis at diagnosis, and post-operative residual disease of greater than $1.5 \mathrm{~cm}^{2}$. These children receive a higher dose of craniospinal irradiation (CSI) of 36 Gy with a posterior fossa boost. ${ }^{2-4}$ This risk stratification strategy for upfront therapy has resulted in significant improvements in overall survival (OS) of children with MB conferring children with standard risk disease a 5-year OS nearing $80 \%$. $^{2}$ However, approximately $40 \%$ of patients with pediatric MB will experience recurrent disease and $30 \%$ will not survive into adulthood. ${ }^{5}$ Reports of phase I and phase II studies for recurrent pediatric MB exist, but the therapies provided have been observed to bear significant treatment-related morbidity and mortality. ${ }^{6}$ One such example is high-dose chemotherapy, and autologous stem cell transplant as a salvage regimen has observed prolonged survival with significant deaths (i.e., 25\%) associated with treatment-related toxicities. ${ }^{7}$ When the benefits of prolonged survival outweigh the risk of the treatment, the hopes for treatment response leave patients and families with little other options.

While there are reports of long-term survivors who have received differing strategies of salvage therapy to treat recurrent $\mathrm{MB}$, no one strategy has proved to be superior to another. ${ }^{8-15}$ With current efforts to identify driver genes for biologically targeted therapies, the heterogeneity of the genetic mutations of these tumors may in part explain the lack of definitive results with respect to benefits relating to morbidity and mortality of early molecularly targeted clinical trials. ${ }^{16,17}$ In the past decade, the international pediatric $\mathrm{MB}$ community identified four distinct molecular subgroups (Wnt, Shh, Group 3, and Group 4) ${ }^{18}$ and described associated clinical outcomes, ${ }^{1,19}$ including recurrence. $^{20}$ The Wnt subgroup tumors are identified by an upregulation of the Wnt pathway and have been observed to experience the most favorable clinical course with current clinical trials designed to explore de-escalation of therapy ${ }^{21-23}$ in this subgroup. The Shh group is characterized by the aberrant activation of the Shh signaling pathway. Recent biological studies suggest these tumors can be stratified into two age-associated subgroups, based on their methylation profiles, with infant Shh (iShh) experiencing a worse prognosis. ${ }^{24}$ Subsequent methylation profiling analysis observed that the iShh group further segregates into two distinct methylation subtypes with associated clinical outcomes. iShhI was associated with a worse prognosis (i.e., 5year progression-free survival (PFS) of $28 \%$ vs. $75 \%$ in iShhII subgroup). ${ }^{25}$ The remaining two subgroups, Group 3 and $4 \mathrm{MB}$, are not characterized by a dominant aberrant signaling pathway, but genetic profiling has verified that they are distinct from Wnt and Shh MB, as well as each other. Group 3 MB (G3 MB) bears the worse prognosis, often metastatic at presentation and is associated with the poorest outcome survival, ${ }^{17,26}$ especially if the tumor cells harbor the upregulation of the MYC oncogene. ${ }^{18}$
Group $4 \mathrm{MB}$ (G4 MB) is the most common subgroup, with an intermediate prognosis, ${ }^{17}$ although metastasis at presentation confers poorer clinical outcome. ${ }^{1}$

In efforts to understand treatment strategies that were historically employed in our single mid-sized Canadian pediatric academic institution, we set out to describe the salvage treatments that have been provided to children with treatment-refractory or recurrent $\mathrm{MB}$ and their overall outcome. In addition, with a rise in molecularly targeted therapy and observations of genetic tumor factors conferring greater risk of relapse, where possible, we have described our cohort in association with available molecular MB subgrouping data.

\section{Methods}

A retrospective chart review of pediatric patients from the McMaster Pediatric Brain Tumour Study Group (PBTSG) was conducted after approval by the Hamilton Integrated Research Ethics Board (HiREB). Patients identified for this study were those who were admitted to McMaster Children's Hospital between 2002 and 2015 and underwent surgical resection (gross total resection [GTR] or subtotal resection [STR], debulking, or biopsy) and subsequently received a histopathological diagnosis of MB. Overall, 31 patients were identified and included in this study. All patients were followed up for at least 2 years. Data including patient demographics, treatment, and outcomes were collected from a combination of electronic health records and paper charts. Molecular subgrouping was either provided by the Clinical Laboratory Improvement Amendments (CLIA)-certified NanoString facility at Toronto Sick Kids Hospital using fresh tissue from 2016 onward or performed in the laboratory of Dr. Sheila Singh from the original tumor sample, stored in RNAlater ${ }^{\circledR}$ (Sigma, \#R0901) or paraffin-embedded samples requested from the Department of Neuropathology. Ten paraffin sections per sample were deparaffinised with xylene prior to RNA extraction using the RNeasy FFPE RNA extraction kit (Qiagen, \#73504) as directed by the manufacturer. RNA concentrations were measured using the NanoDrop 1000 instrument (NanoDrop), and the RNA integrity was assessed at the McMaster Illumina facility. Using the Northcott MB CodeSet, ${ }^{27}$ raw NanoString counts for each gene were normalized. The normalized data were subsequently $\log _{2}$-transformed and used as an input for class prediction as previously described. ${ }^{26}$

Descriptive statistics were performed, with categorical variables reported as counts and percentages and continuous variables as mean with standard deviation or median with range. Kaplan-Meier analysis was performed to estimate cumulative recurrence-free and survival rates with $95 \%$ confidence intervals, and log-rank test was used for between-group comparisons. A $p$-value of 0.05 was considered for statistical significance. SPSS version 25.0 (www.ibm.com) ${ }^{28}$ was used for data analysis.

\section{Results}

Over the 13-year period, a total of 31 children with a diagnosis of MB were consecutively treated and included in this study. Table 1 summarizes the main patient demographics. The majority of patients were male and non-infants with a median age of 8 years (16.6 years) and median follow-up of 64.8 months (168 months). The dominant histopathological subtype was large cell anaplastic, although a significant proportion did not have the 
Table 1: Patient Demographics $(n=31)$

\begin{tabular}{|c|c|c|}
\hline & Total & $n(\%)$ \\
\hline Total & 31 & \\
\hline \multicolumn{3}{|l|}{ Gender } \\
\hline Male & & $21(67.7)$ \\
\hline Female & & $10(32.3)$ \\
\hline Median age (SD) & & $8.0(16.6)$ \\
\hline \multicolumn{3}{|l|}{ Histopathology } \\
\hline Classic & & $6(20.7)$ \\
\hline Large cell anaplastic & & $8(27.6)$ \\
\hline High grade & & $2(6.9)$ \\
\hline Desmoplastic/nodular & & $5(17.2)$ \\
\hline Not specified & & $10(32.3)$ \\
\hline \multicolumn{3}{|c|}{$\begin{array}{l}\text { Molecular } \\
\text { subgrouping data available }\end{array}$} \\
\hline Total & & $8(25.8)$ \\
\hline Wnt & & $2(25.0)$ \\
\hline Shh & & $2(25.0)$ \\
\hline G3 & & $0(0.0)$ \\
\hline G4 & & $4(50.0)$ \\
\hline \multicolumn{3}{|l|}{$\begin{array}{l}\text { CSF-seeding } \\
\text { pre-operatively }\end{array}$} \\
\hline Total & & $7(22.6)$ \\
\hline No & & $5(16.1)$ \\
\hline Yes & & $0(0.0)$ \\
\hline Not discernable & & $2(6.4)$ \\
\hline Not available & & $1(3.2)$ \\
\hline \multicolumn{3}{|c|}{ CSF-seeding $10-14$ days post-operatively } \\
\hline Total & & $24(77.4)$ \\
\hline No & & $16(66.7)$ \\
\hline Yes & & $5(20.8)$ \\
\hline Not discernable & & $3(9.6)$ \\
\hline \multicolumn{3}{|l|}{ Recurrence } \\
\hline Total & & $13(41.9)$ \\
\hline Age $<3$ years & & $5(38.4)$ \\
\hline Age $>3$ years & & $8(61.5)$ \\
\hline \multicolumn{3}{|c|}{ Recurrence in those with molecular subgroups } \\
\hline Total & & $5(38.5)$ \\
\hline Wnt & & $0(0)$ \\
\hline Shh, p53 WT & & $2(40.0)$ \\
\hline G4 & & $3(60.0)$ \\
\hline Overall survival (OS) & & $20(64.5)$ \\
\hline $\begin{array}{l}\text { 5-year recurrence-free } \\
\text { survival }\end{array}$ & & 18 (55.7\%; 95\% CI: $37.5 \%-73.7 \%)$ \\
\hline 5 -year OS & & $20(62.8 \% ; 95 \%$ CI: $45.0 \%-80.5 \%)$ \\
\hline
\end{tabular}

WT = wild type; G4 = Group 4. subtype specified. Eight patients underwent pre-operative cerebrospinal fluid (CSF) analysis to identify CSF-seeding of the tumor with all of the results reported as negative or indiscernible. Of the 24 patients who underwent a lumbar puncture 10-14 days post-operatively, 5 patients $(20.5 \%)$ had a positive result. Thirteen $(41.9 \%)$ patients had recurrent or treatment-refractory MB; three $(23.1 \%)$ of these patients were infants. At 5 years, the recurrence-free survival was $55.7 \%$ (95\% CI: $37.5 \%-73.7 \%$ ) and the OS was $62.8 \%$ (95\% CI; $45.0 \%-80.5 \%$ ).

\section{Progressive or Recurrent Disease Carries Significant Mortality Especially in the Infant Group}

The median time to either disease progression or recurrence was 14.6 months from the first presentation (Table 2). Thirteen of $31(41.9 \%)$ children were found to have metastatic disease at presentation. Furthermore, children presenting with metastatic disease had a higher likelihood of recurrence (6 of $13(46.2 \%)$ vs. 7 of $18(38.9 \%)$ ). Recurrence in infants occurred earlier than in non-infants (median 3.1 months (28.0 months) vs. 15.1 months (35.0 months) (Figure 1A), and infants with recurrence had a shorter median follow-up (i.e., 7.2 months (45.6 months)) compared to non-infants (i.e., 39.6 months (69.5 months)), as the tumor in these patients tended to return or progress aggressively and was more likely to be palliated. Patients who experienced recurrence and were alive at the time of writing had a median follow-up of 58.8 months (38.4 months) since admission, and of these children, two out of four $(50.0 \%)$ had metastasis at presentation. Comparatively, patients who experienced recurrence and were deceased had a median follow-up of 25.2 months (53 months) since admission, and four out of nine (44.4\%) had metastasis at presentation. With respect to the location of recurrence, among the 13 patients who had progression or recurrence of their tumor, only 3 (23.1\%) experienced local disease progression/recurrence while the remaining 10 patients (76.9\%) recurred with disseminated leptomeningeal spread (Table 3). Median time to recurrence was 15.1 months $(7$ months) for patients with local recurrence, compared to 13.5 months (35 months) for patients with leptomeningeal spread (Figure 1B). While none of the patients with local recurrence had metastasis at presentation, 6 out of $10(60.0 \%)$ patients with leptomeningeal spread had metastasis at the time of the first presentation. Although all the children within the local recurrence group were alive with stable disease at the time of writing, none had reached the 5 years of follow-up (range: 0.7-2.1 years). In the group experiencing leptomeningeal recurrence, however, two (20\%) were alive more than 5 years after an initial diagnosis with three (33.3\%) alive with stable disease and a median follow-up of 5.4 years (6.4 years) at the time of writing. Median follow-up after recurrence was 10.2 months (23 months) in the local group, compared to 14.5 months ( 75 months) in the leptomeningeal group.

\section{Post-Progression or Disease Recurrence Management}

In 3 of the $13(23.1 \%)$ patients experiencing recurrent MB the disease had significantly progressed, and patients were palliated (Table 4), with a median time to recurrence of 3.0 months (4 months). Two of these children had metastasis at presentation, with a median follow-up of 3.0 months since admission (4.8 months); median follow-up since recurrence was 0.1 months 
Table 2: Age stratification into infant and non-infant populations and clinical characteristics

\begin{tabular}{|c|c|c|c|c|c|}
\hline & Total & $\begin{array}{c}\text { Median Time to } \\
\text { Recurrence Months } \\
\text { (Range) }\end{array}$ & $\begin{array}{c}\text { Metastasis at } \\
\text { Presentationn (\%) }\end{array}$ & Overall Survivaln (\%) & $\begin{array}{c}\text { Median Follow-UpMonths } \\
\text { (Range) }\end{array}$ \\
\hline Total & 31 & & & & \\
\hline All patients & & & $13(41.9)$ & $20(64.5)$ & $64.8(168.0)$ \\
\hline Age $<3$ years & 5 & & $2(40.0)$ & $3(60.0)$ & $46.8(110.5)$ \\
\hline Age $>3$ years & 26 & & $11(42.3)$ & $17(65.4)$ & $66.0(163.2)$ \\
\hline \multicolumn{6}{|l|}{ No recurrence } \\
\hline Total & 18 & & $7(38.9)$ & $16(88.9)$ & $106.0(163.2)$ \\
\hline Age $<3$ years & 2 & & $0(0.0)$ & $2(100)$ & $108.6(6.0)$ \\
\hline Age $>3$ years & 16 & & $7(43.8)$ & $14(87.5)$ & $99.0(163.2)$ \\
\hline \multicolumn{6}{|l|}{ Recurrence } \\
\hline Total & 13 & $14.6(35.0)$ & $6(46.2)$ & $4(30.8)$ & $38.4(75.6)$ \\
\hline Age $<3$ years & 3 & $3.1(28.0)$ & $2(66.7)$ & $1(33.3)$ & $7.2(45.6)$ \\
\hline Age $>3$ years & 10 & $15.1(35.0)$ & $4(40.0)$ & $3(30.0)$ & $39.6(69.5)$ \\
\hline Alive & 4 & $13.6(31.0)$ & $2(50.0)$ & & $58.8(38.4)$ \\
\hline Deceased & 9 & $14.6(35.0)$ & $4(44.4)$ & & $25.2(53.0)$ \\
\hline
\end{tabular}

A

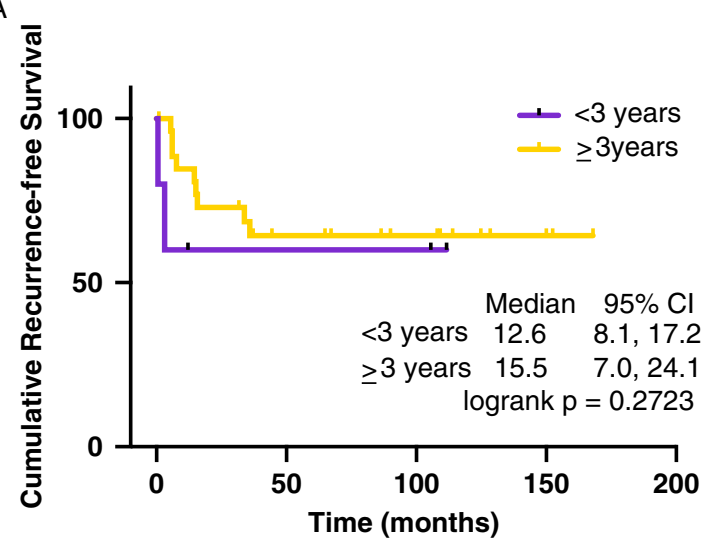

Number at risk

\begin{tabular}{ccccccccc}
\hline Time (months) & 0 & 24 & 36 & 60 & 84 & 108 & 144 & 168 \\
\hline$\leq 3$ years & 5 & 3 & 2 & 2 & 2 & 1 & & \\
$\geq 3$ years & 26 & 17 & 12 & 10 & 8 & 5 & 2 & 1 \\
\hline
\end{tabular}

$\mathrm{B}$

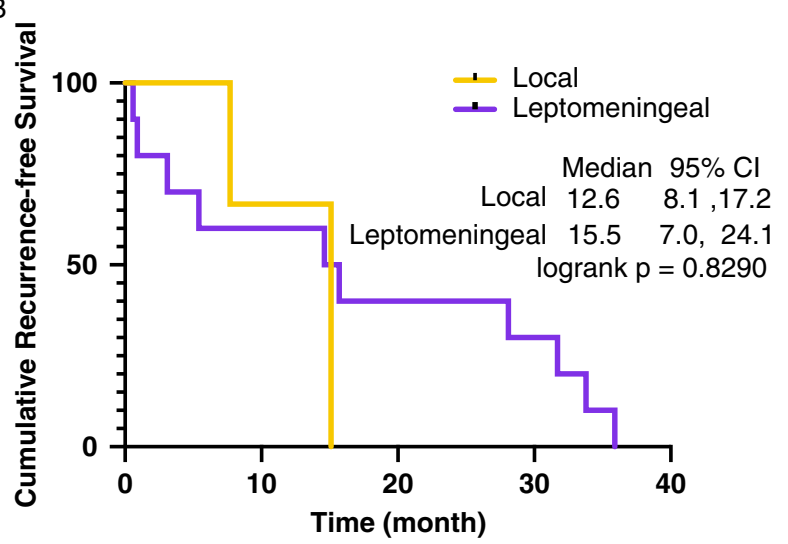

Number at risk

\begin{tabular}{llllllll}
\hline Time (months) & 0 & 6 & 12 & 18 & 24 & 30 & 36 \\
\hline Local & 3 & 3 & 2 & & & & \\
Leptomeningeal & 10 & 6 & 6 & 4 & 4 & 3 & 1 \\
\hline
\end{tabular}

Figure 1: Cumulative recurrence-free survival by age and pattern of recurrence. (A) Cumulative recurrence-free survival by age and (B) cumulative recurrence-free survival by pattern of recurrence with associated at risk tables.

(1.2 months). The remaining 10 (76.9\%) children underwent some form of salvage therapy that was delivered in isolation or in combination with the other modalities. The treatments provided included surgical re-resection, radiation (CSI, whole-brain irradiation, or focal stereotactic irradiation delivered via a robotic arm called CyberKnife ${ }^{\circledR}$ ), drugs such as imatinib, etoposide, vinblastine, temsirolimus, tipifarnib, temozolamide, and irinotecan, either in isolation or in varying combinations. Among patients who received salvage therapy, follow-up since presentation ranged from 7.2 to
76.8 months, while follow-up since recurrence ranged from 0.4 to 75.8 months. Of the 10 patients who received salvage therapy, 4 (40.0\%) were alive at the time of writing (Table 5). Three out of the four children experienced leptomeningeal dissemination.

Of note, there were two patients who did not experience recurrence but died secondary to other medical complications. One patient died from respiratory compromise in hospital, and the second patient from neutropenic colitis, acute respiratory distress syndrome (ARDS), and subsequent cardiorespiratory arrest. Both 
Table 3: Medulloblastoma recurrence pattern

\begin{tabular}{l|c|c|c|c|c|c}
\hline Pattern of Spread & Total & $\begin{array}{c}\text { Median Time to } \\
\text { Recurrence Months } \\
\text { (Range) }\end{array}$ & $\begin{array}{c}\text { Metastasis at } \\
\text { Presentation } \boldsymbol{n}(\boldsymbol{\%})\end{array}$ & $\begin{array}{c}\text { Overall Survival } \boldsymbol{n} \\
\mathbf{( \% )}\end{array}$ & $\begin{array}{c}\text { Median Follow-Up } \\
\text { Months (Range) }\end{array}$ & $\begin{array}{c}\text { Median Follow-Up } \\
\text { after Recurrence } \\
\text { Months (Range) }\end{array}$ \\
\hline Total & 13 & $15.0(35.0)$ & $6(46.2)$ & $4(30.8)$ & $38.5(75.5)$ & $10.0(75.5)$ \\
\hline Local & 3 & $15.1(7.0)$ & $0(0.0)$ & $1(33.3)$ & $25.2(30.0)$ & $10.2(23.0)$ \\
\hline Leptomeningeal & 10 & $13.5(35.0)$ & $6(60.0)$ & $3(30.0)$ & $43.8(75.5)$ & $14.5(75.6)$ \\
\hline
\end{tabular}

Table 4: Salvage therapy received in patients with recurrence $(n=13)$

\begin{tabular}{|c|c|c|c|c|c|c|}
\hline Salvage Therapy & Total & $\begin{array}{c}\text { Median time to } \\
\text { Recurrence Months } \\
\text { (Range) }\end{array}$ & $\begin{array}{c}\text { Metastasis at } \\
\text { Presentation } n(\%)\end{array}$ & $\begin{array}{c}\text { Overall Survival } \\
n(\%)\end{array}$ & $\begin{array}{l}\text { Median Follow-Up } \\
\text { Months (Range) }\end{array}$ & $\begin{array}{c}\text { Median Follow-Up } \\
\text { after Recurrence } \\
\text { Months (Range) } \\
\end{array}$ \\
\hline Palliated & 3 & $3.0(4.0)$ & $2(66.7)$ & $0(0.0)$ & $7.2(6.0)$ & $2.2(4.0)$ \\
\hline CSI & 1 & 15.0 & $0(0.0)$ & $1(100)$ & 38.4 & 23.4 \\
\hline $\begin{array}{l}\text { CSI, vincristine, cisplatin, } \\
\text { cyclosphamide }\end{array}$ & 1 & 1.0 & $1(100)$ & $1(100)$ & 76.8 & 75.8 \\
\hline Oral etoposide & 1 & 8.0 & $0(0.0)$ & $0(0.0)$ & 8.4 & 0.4 \\
\hline Carboplatin, etoposide, imatinib & 1 & 36.0 & $0(0.0)$ & $0(0.0)$ & 40.8 & 4.8 \\
\hline Cyberknife® & 2 & $15.5(1.0)$ & $1(50.0)$ & $0(0.0)$ & $25.2(0)$ & $9.7(1.0)$ \\
\hline Imatinib, tipifarnib & 1 & 15.0 & $0(0.0)$ & $0(0.0)$ & 50.4 & 35.4 \\
\hline $\begin{array}{l}\text { Surgery, Cyberknife®, } \\
\text { temozolomide }\end{array}$ & 1 & 34.0 & $1(100)$ & $0(0.0)$ & 54.0 & 20.0 \\
\hline $\begin{array}{l}\text { Cyberknife®, vinblastine, } \\
\text { temsirolimus, temozolamide, } \\
\text { irinotecan, bevacizumab, } \\
\text { intrathecal topotecan }\end{array}$ & 1 & 32.0 & $1(100)$ & $1(100)$ & 70.8 & 38.8 \\
\hline $\begin{array}{l}\text { Whole-brain irradiation, } \\
\text { temozolomide, irinotecan, } \\
\text { methotrexate, carboplatin, } \\
\text { thiopenta }\end{array}$ & 1 & 28.0 & $0(0.0)$ & $1(100)$ & 46.8 & 7.2 \\
\hline
\end{tabular}

CSI = craniospinal irradiation.

were stratified as high-risk MB patients, underwent GTR, and were subsequently treated with chemotherapy (vincristine, cisplatin, cyclophosphamide, etoposide) in addition to CSI with a posterior fossa boost.

\section{Molecular Subgrouping and Clinical Outcomes}

Molecular subgrouping was available for eight patients (Table 6). Two were Wnt MB, and neither experienced recurrence and were alive with stable disease for a mean of 3.4 years (3.1-3.7). Two patients' tumors had a significant Shh pathway activation with recurrent disease experienced by both patients. One was an infant with a desmoplastic nodular histological appearance with p53 wild type (WT) immunoreactivity, and the other anaplastic histological appearance and also p53 WT. The remaining four patients were G4 MB. One G4 MB had an STR, metastatic at presentation and risk stratified into high-risk upfront therapy and disease-free 5.6 years since presentation at the time of writing. Three of the four G4 MB were metastatic at presentation and risk stratified into high-risk therapy with two recurring 33.8 and 15.1 months after presentation. One experienced progressive disease despite re-resection, focal re-irradiation more than 2 years after their first exposure to CSI in addition to temozolamide and etoposide and therefore palliated. The second patient received focal irradiation via CyberKnife ${ }^{\circledR}$ but was palliated due to complications of the adjuvant therapy. The standard risk G4 MB patient experienced recurrence 15.1 months after GTR, had CSI for salvage therapy, and was alive 2 years with stable disease since the recurrence.

\section{Discussion}

This retrospective single center study highlights the heterogeneity of salvage treatments provided to children with treatmentrefractory or recurrent MB between 2003 and 2015.

\section{Timing and Pattern of Recurrence}

Thirty-one children with a diagnosis of MB were treated in our institution over a 13-year period. Similar to other pediatric MB cohorts, our cohort consisted of infants and children with a predilection of disease in males and lower incidence in children 
Table 5: Description of treatment course for survivors receiving salvage therapy $(n=4)$

\begin{tabular}{|c|c|c|c|c|c|c|c|}
\hline Age Group & $\begin{array}{c}\text { Treatment Prior to } \\
\text { Progression/ Recurrence }\end{array}$ & $\begin{array}{c}\text { Time to } \\
\text { Recurrence } \\
\text { (Months) }\end{array}$ & $\begin{array}{l}\text { Metastasis at } \\
\text { Presentation }\end{array}$ & $\begin{array}{l}\text { Pattern of } \\
\text { Recurrence }\end{array}$ & Salvage Therapy Provided & Disease Status & $\begin{array}{l}\text { Follow-Up } \\
\text { since } \\
\text { Recurrence } \\
\text { (Months) } \\
\end{array}$ \\
\hline Non-infant & $\begin{array}{l}\text { Surgical resection } \\
\text { (radiological residual); } \\
\text { ACNS0332 } \\
\text { (chemotherapy, } \\
\text { autologous stem } \\
\text { hematopoietic stem cell } \\
\text { transplantation) }\end{array}$ & 0.9 & Yes & $\begin{array}{c}\text { Leptomeningeal } \\
\text { dissemination }\end{array}$ & $\begin{array}{l}\text { Rapid progression post-resection; } \\
\text { received chemotherapy } \\
\text { (vincristine, cisplatin, } \\
\text { cyclophosphamide), CSI }(39.6 \mathrm{~Gy}), \\
\text { posterior fossa boost }(14.4 \mathrm{~Gy})\end{array}$ & $\begin{array}{l}\text { Stable residual, no } \\
\text { progression }\end{array}$ & 76.8 \\
\hline Non-infant & $\begin{array}{l}\text { Surgical resection (no } \\
\text { radiological residual); } \\
\text { chemotherapy } \\
\text { (ACNS0332: } \\
\text { chemotherapy); } \\
\text { CSI ( } 36 \mathrm{~Gy} \text { ); posterior } \\
\text { fossa boost (19.8 Gy) }\end{array}$ & 31.7 & Yes & $\begin{array}{l}\text { Leptomeningeal } \\
\text { dissemination }\end{array}$ & $\begin{array}{l}\text { CyberKnife } ® \text { and chemotherapy } \\
\text { (vinblastine, temsirolimus); } \\
\text { progression; switched to } \\
\text { temozolomide, irinotecan, } \\
\text { bevacizumab; further progression; } \\
\text { Ommaya reservoir for intrathecal } \\
\text { topotecan); further progression; } \\
\text { significant response to palliative } \\
\text { whole-brain re-irradiation }\end{array}$ & $\begin{array}{l}\text { After intraventricular } \\
\text { topotecan } \\
\text { commenced, tumor } \\
\text { residual is stable and } \\
\text { had not progressed }\end{array}$ & 70.8 \\
\hline Non-infant & $\begin{array}{l}\text { Surgical resection (no } \\
\text { radiological residual); } \\
\text { ACNS0334 } \\
\text { (chemotherapy, } \\
\text { autologous hematopoietic } \\
\text { stem cell transplantation); } \\
\text { CSI ( } 36 \text { Gy); posterior } \\
\text { fossa boost (19.8 Gy) }\end{array}$ & 15.1 & No & Local & $\begin{array}{l}\text { CSI (36 Gy), posterior fossa boost } \\
\text { (18 Gy) }\end{array}$ & $\begin{array}{l}\text { No evidence of } \\
\text { recurrent nor residual } \\
\text { disease }\end{array}$ & 38.4 \\
\hline Infant & $\begin{array}{l}\text { Surgical resection; } \\
\text { chemotherapy } \\
\text { (ACNS1221 off study) } \\
\text { with high-dose } \\
\text { methotrexate. Reduction } \\
\text { of radiological residual } \\
\text { but underwent second } \\
\text { surgery achieving gross } \\
\text { total resection }\end{array}$ & 12.1 then 28.1 & No & $\begin{array}{l}\text { Leptomeningeal } \\
\text { dissemination } \\
\text { then distant single } \\
\text { left frontal } \\
\text { metastasis }\end{array}$ & $\begin{array}{l}\text { Emergency } 5.4 \text { Gy craniospinal } \\
\text { irradiation, re-induction and } \\
\text { consolidation therapy as per } \\
\text { ACNS } 0334 \text { and autologous triple } \\
\text { stem cell rescue } \\
\text { Left frontal meningeal lesion was } \\
\text { resected; craniospinal irradiation } \\
\text { (36 Gy + } 18 \text { Gy boost to original } \\
\text { and left frontal surgical beds) }\end{array}$ & $\begin{array}{l}\text { Stable disease, no } \\
\text { evidence of } \\
\text { recurrence }\end{array}$ & 7.2 \\
\hline
\end{tabular}

CSI = craniospinal irradiation.

less than 3 years of age. ${ }^{23,29-31}$ Thirteen of 31 children experienced treatment-refractory disease, local recurrence, distant metastases, or florid leptomeningeal dissemination. We included children who had at least 2 years of follow-up data because it is generally believed that once the child has completed the treatment course, and his or her 2-year follow-up imaging is free of disease, the child is generally considered to have a more favorable prognosis compared to those with imaging suggestive of progressive disease. ${ }^{32,33}$ However, in a recent large multicenter study that analyzed the survival of children with recurrent $\mathrm{MB}$, it was noted that risk-based therapy results in relatively stable 5-year PFS and OS rates but with tumor recurrence observed in a significant number of children out with the 5-year interval. ${ }^{34}$ Similarly, in our cohort there were three children who had recurrence of their disease out with the 2-year window. Comparable to Koschmann et al.'s cohort who had a median time to recurrence of 18 months, ${ }^{31}$ our cohort had a median time to recurrence of 15.0 months (35.0 months) from the date of admission, and as expected the children requiring salvage therapy were more likely to have presented with evidence of radiological metastasis. As previously described ${ }^{23}$ phenotypically more aggressive disease was also observed in our infant cohort as compared to non-infants with earlier recurrence (3.1 vs. 15.1 months) and shorter survival (3.0 vs. 33.6 months). Given the small numbers of patients with molecular subgrouping data in our cohort, we observed recurrence in $60 \%$ (i.e., 3 of 5) of the subgrouped within the 2-year interval (Table 6).

Although none of the children in our locally recurring MB cohort presented with metastatic disease, this group had a comparable 5-year OS to the leptomeningeal recurrence cohort suggesting that recurrent disease is a poor prognostic indicator irrespective of its pattern of disease. Ramaswamy et al. were the first to describe the timing and pattern of $\mathrm{MB}$ recurrence in molecularly subgrouped $\mathrm{MB}$, observing $\mathrm{G} 4 \mathrm{MB}$ tumors to have the longest recurrence-free interval and post-recurrence survival. ${ }^{19} \mathrm{G} 3 \mathrm{MB}$ tumors were observed to experience the opposite clinical course (i.e., shortest recurrence-free and post-recurrence survival interval). In contrast to Ramaswamy et al.'s description of Shh tumors more commonly experiencing local recurrence with metastatic recurrence occurring more commonly in G3 or G4 MB tumours, ${ }^{19}$ in our small cohort of subgrouped recurrent $\mathrm{MB}$ cohort, we observed the opposite pattern with both our Shh subgrouped patients recurring with florid disseminated disease and the G4 MB recurring locally. 


\section{Table 6: Clinical course and outcomes of children with molecular subgrouping data $(n=8)$}

\begin{tabular}{|c|c|c|c|c|c|c|c|c|c|c|}
\hline Age group & $\begin{array}{l}\text { Molecular } \\
\text { Subgroup }\end{array}$ & $\begin{array}{l}\text { Metastasis at } \\
\text { Presentation }\end{array}$ & $\begin{array}{l}\text { Extent of } \\
\text { Resection }\end{array}$ & $\begin{array}{c}\text { Risk } \\
\text { Stratification }\end{array}$ & Recurrence & $\begin{array}{c}\text { Time to } \\
\text { Recurrence } \\
\text { (Months) } \\
\end{array}$ & Salvage Therapy Provided & Disease Status & Outcome & $\begin{array}{c}\text { Follow-Up } \\
\text { (Years) }\end{array}$ \\
\hline Non-infant & Wnt & No & GTR & Standard & No & - & - & Stable & Alive & 3.7 \\
\hline Non-infant & Wnt & No & GTR & Standard & No & - & - & Stable & Alive & 3.1 \\
\hline Infant & $\begin{array}{l}\text { Shh, p53 WT, } \\
\text { MYCN } \\
\text { amplification }\end{array}$ & No & STR & Standard & Yes & $\begin{array}{l}12.1 \text { then } 28.1 \\
\text { from previous } \\
\text { recurrence }\end{array}$ & $\begin{array}{l}\text { Rapid disseminated recurrence } 3 \text { months post- } \\
\text { completion of chemotherapy, emergency } 5.4 \text { Gy } \\
\text { craniospinal irradiation, re-induction and } \\
\text { consolidation therapy as per ACNS0334 and } \\
\text { autologous triple stem cell rescue } \\
\text { Significant response for } 2 \text { years but then recurred } \\
\text { with a left frontal meningeal lesion which was } \\
\text { resected; craniospinal irradiation ( } 36 \mathrm{~Gy}+18 \mathrm{~Gy} \\
\text { boost to left frontal surgical bed) }\end{array}$ & Stable & Alive & 3.9 \\
\hline Non-infant & $\begin{array}{l}\text { Shh, p53 WT, } \\
\text { MYCN } \\
\text { amplification }\end{array}$ & Yes & GTR & High & Yes & 31.7 & $\begin{array}{l}\text { CyberKnife® and chemotherapy (vinblastine, } \\
\text { temsirolimus); progression; switched to } \\
\text { temozolomide, irinotecan, bevacizumab; further } \\
\text { progression; Ommaya reservoir for intrathecal } \\
\text { topotecan); further progression; significant } \\
\text { response to palliative whole-brain re-irradiation }\end{array}$ & Stable & Alive & 5.9 \\
\hline Non-Infant & G4 & No & GTR & Standard & Yes & 15.1 & CSI & Stable & Alive & 3.2 \\
\hline Non-infant & $\begin{array}{l}\text { G4, MYCN } \\
\text { amplification }\end{array}$ & Yes & STR & High & No & - & - & Stable & Alive & 5.6 \\
\hline Non-infant & G4 & Yes & STR & High & Yes & 33.8 & Surgery, CyberKnife $®$, temozolomide, etoposide & Progressive & Deceased & 4.5 \\
\hline Non-infant & G4 & No & STR & High & Yes & 15.1 & CyberKnife® & $\begin{array}{c}\text { Palliated with } \\
\text { complications of adjuvant } \\
\text { therapy }\end{array}$ & Deceased & 2.1 \\
\hline
\end{tabular}

WT $=$ wild type; Wnt $=$ Wingless; Shh $=$ Sonic hedgehog; G4 = Group 4 molecular subgroups; CSI $=$ craniospinal irradiation. 


\section{Salvage Therapy Provided}

The salvage therapy provided to our cohort of children was largely dependent on the upfront treatment administered after the initial resection. At disease progression or recurrence, the armamentarium for salvage therapy includes second surgery, chemotherapy, and radiotherapy. Although Johnston et al. demonstrated that once MB has recurred, the probability of regaining tumor control is poor, ${ }^{32}$ and this observation may be more speaking to the lack of salvage therapy available to the child because of the treatment that patient has already received, poor tolerability of the salvage therapy, the child's neurological status, and bone marrow and end-organ function. In three patients experiencing recurrence/disease progression (23\%), the disease progressed beyond that would have been amenable to salvage therapy and therefore managed expectantly on a palliative care pathway. In the remaining 10 children $(77 \%)$ however, a number of salvage therapy protocols were provided based on available clinical trials with 6 of the children in our cohort (i.e., 6/10 recurrent/treatmentrefractory $\mathrm{MB}$ receiving salvage therapy, 60\%) succumbing to recurrent/progressive disease. Their clinical course is comparable to other large pediatric MB datasets, where they were more likely to be metastatic at presentation, with a poor OS. ${ }^{1,35}{ }^{37}$ Of interest, half of the surviving recurrent children continue to survive their disease despite their metastatic status at presentation (Table 5).

The location of disease recurrent was insignificant for OS in our cohort. Of the three children who presented with local disease progression/recurrence, only one was alive at the time of writing. The first child who died of local progression showed extension of the recurrent lesion from the original tumor bed, crossing the midline into both cerebellar peduncles and the midbrain. He was administered etoposide but was palliated and died shortly thereafter. The second child succumbed to the disease after Cyberknife ${ }^{\circledR}$ focal irradiation treatment was complicated by pancytopenia, infection, encephalitis, status epilepticus, and disseminated intravascular coagulation. Both of these children had an intraoperative surgical impression of GTR, and neither had a radiological residual tumor detected on post-operative MRI. The third child, currently surviving a local recurrence, was initially treated under the standard risk regimen and was alive at the time of writing, 1.5 years after receiving CSI as salvage therapy. This case in particular highlights the role of re-irradiation as a salvage therapy to be considered, particularly for the relapsed standard risk patients. ${ }^{38}$

Of the children recurring with leptomeningeal dissemination, three were palliated (i.e., two infants, one non-infant) due to the extensive form of disease. Of the remaining seven children, one was an infant with desmoplastic nodular histology and Shh subgrouping recurred with leptomeningeal dissemination (Case 3). Of the six non-infants experiencing leptomeningeal disseminated recurrences, two were alive at the time of writing. One child recurred and progressed through multiple salvage strategies with disease control with whole brain re-irradiation (Case 2). The remaining non-infant patient experienced a rapid progression prior to CSI treatment, and disease control was achieved with urgent CSI, vincristine, cisplatin, and cyclophosphamide (Case 1). Both these non-infant children were diagnosed with an anaplastic histopathological subtype with the former patient's tumor subgrouped as a Shh. The latter patient's subgroup was yet to be determined.

\section{Treatment of Recurrent Pediatric MB in the Molecular Era}

When molecular subgrouping for pediatric MB became the standard of care, the opportunities to understand the biological mechanism of disease and consequently options for postresection adjuvant therapy experienced a significant development. Furthermore, a deeper insight into which MB subgroups are associated with a favorable prognosis and therefore can be considered for de-escalation therapy became a rationalizable option. While the patient management of recurrent MB historically focused on the quality of the remaining life of the child rather than curative strategies, informed by the molecular data from childhood MB tumor samples, and in collaboration with drug companies, pediatric neurooncologists and the scientific community have been able to explore the possibility of individualized targeted therapy. ${ }^{39}$ The recognition of the genetic subgroups of pediatric $\mathrm{MB}^{17}$ and its incorporation into the 2016 WHO Classification of tumors of the central nervous system ${ }^{40}$ have led to a change in clinical management of our locally treated patients where all samples are now sent to a CLIA-certified laboratory for molecular subgrouping. Although subgroups are believed to remain stable at recurrence. ${ }^{19,41}$ Hill et al. identified new mutations that occur in all subgroups (e.g., $M Y C / M Y C N$ amplification and p53 mutation) at relapse following the standard upfront therapy, ${ }^{42}$ suggesting a divergence in genetic profiles of MB tumors at recurrence as Morrissy et al. observed. ${ }^{43}$ Not unexpectedly, however, the only survivors after salvage therapy in Hill et al.'s cohort were of the Wnt subtype. In our surviving recurrent pediatric $\mathrm{MB}$ cohort, however, two patient tumors were subgrouped as Shh without p53 mutation, one G4 MB of classic histology and the remaining of unknown molecular subgrouping (Table 6).

\section{Case 1: A Very Young Metastatic G4 MB Successfully Salvaged with CSI and Chemotherapy}

One of the four patient survivors was molecularly subgrouped as G4 MB with metastasis at presentation but, given their young age, underwent a radiation sparing protocol only to progress soon after the completion of consolidation therapy and autologous stem cell rescue. According to Ramaswamy et al., molecular risk stratification for this patient was very high-risk secondary to the G4 MB subgrouping with metastasis at presentation. ${ }^{1}$ As expected, despite upfront radiation sparing therapy, this young child recurred with leptomeningeal dissemination. At the time of recurrence, the child was old enough to receive full dose CSI with a posterior fossa boost and chemotherapy and has had stable disease for over 5 years.

\section{Case 2: Non-Infant Shh Successfully Salvaged with Multiple Agents and Modalities}

The first of two Shh subgrouped tumor patients was diagnosed just before their ninth birthday. No germline mutations were identified, and they received upfront therapy according to highrisk group stratification. ${ }^{2}$ They were salvaged with focal irradiation using CyberKnife $₫$ of the local recurrence in the tumor bed and adjuvant chemotherapy. Having progressed mainly intraventricularly subsequent salvage therapy involved an Ommaya reservoir insertion for intrathecal topotecan. The intraventricular component remained stable until a follow-up MRI just under a 


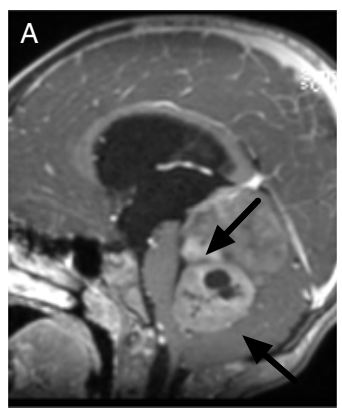

Original presentation

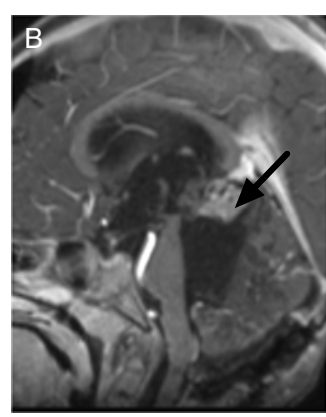

Post-operative radiological residual

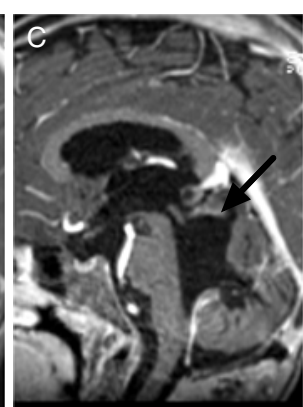

7 month postresection after induction therapy

(ACNS1221)

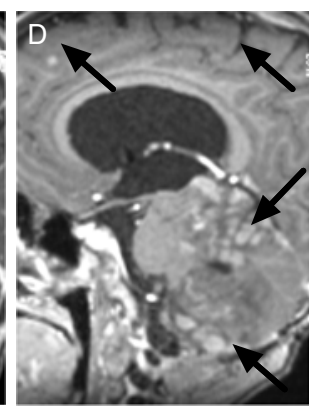

3 months postconsolidation therapy (ACNS1221)

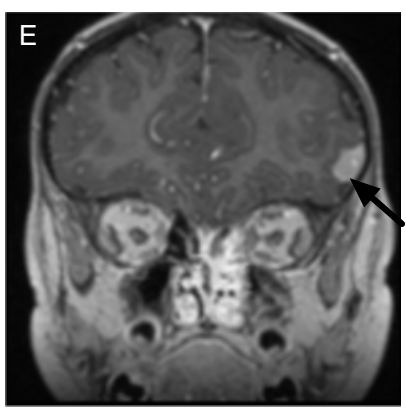

28 months postemergency $5.4 \mathrm{~Gy}$ craniospinal irradiation, re-reinduction, consolidation and stem cell rescue (ACNSO334)

Figure 2: Radiological images of a local and distant recurrent infant desmoplastic nodular medulloblastoma. (A) At presentation, a heterogeneously enhancing large posterior fossa lesion with associated hydrocephalus, (B) Post-operative $1.8 \mathrm{~mm}$ residual at the superior border of fourth ventricle, (C) 7 months after adjuvant induction chemotherapy (ACNS1221) showing reduction in size of the residual, (D) 3 months post-completion of consolidation therapy (ACNS1221) showing rapid recurrence with diffuse leptomeningeal disease, And (E) 21 months post-completion of emergency 5.4 Gy craniospinal irradiation and re-induction and consolidation therapy (ACNSO334) showing left frontal avidly enhancing leptomeningeal lesion.

year later revealed florid recurrence. At this time, no curative option was available, but palliative whole-brain radiation in the form of 20 Gy in five fractions was offered to prolong survival. The intracranial tumors had a remarkable response, and the patient is currently monitored expectantly with the radiation oncologists' recommendations that if there is limited growth of $<2$ lesions, focal irradiation with CyberKnife ${ }^{\circledR}$ would be an option. This case illustrates the important role of re-irradiation in pediatric $\mathrm{MB}$, if safe to deliver, to provide long-term tumor control. A case series of patients from St. Jude's with recurrent MB treated with or without re-irradiation observed a striking benefit of re-irradiation in the standard risk group with a 10-year OS of $45 \%$ in those who were irradiated and $0 \%$ for the patients who did not receive re-irradiation $(p=0.036) .{ }^{36}$ Similar 10-year OS benefit was observed in the high-risk group $(p=0.003)$ with the caveat that the analysis was limited by the small number of patients in this cohort. Fortunately, this patient's very aggressive tumor recurrence responded to whole-brain re-irradiation, provided as a palliative therapy, with stable disease and unexpected functional recovery for the last 6 months at the time of writing.

\section{Case 3: Desmoplastic Nodular Infant Shh MB with Recurrence and Effective Salvage}

An infant diagnosed just before his second birthday presented with a 1-month history of failure to thrive and persistent vomiting. Imaging demonstrated a large posterior fossa mass with associated severe hydrocephalus but no evidence of metastatic disease (Figure 2A). The intraoperative impression was GTR, but the post-operative MRI identified a $1.9 \mathrm{~cm}$ residual (Figure 2B) and the histopathological diagnosis of desmoplastic nodular MB. Given the patient's age, histology suggestive of better prognostic type of MB, the molecular subgroup suggestive of Shh pathway activation, and the HIT-SKK European MB trials ${ }^{44}$ suggesting Shh MB making up the majority of desmoplastic nodular MB, have a much better prognosis, the traditional intensive chemotherapy with autologous stem cell transplant was thought to be too toxic, and therefore the patient underwent an intermediate dose chemotherapy protocol (ACNS1221). Although the residual reduced to half the size (Figure 2C) after the initial three cycles of induction chemotherapy (i.e., vincristine, high-dose methotrexate, carboplatin, etoposide, cyclophosphamide, MESNA), following careful multidisciplinary team consideration, the patient underwent a second-look surgery to resect the residual tumor, achieving GTR. When the residual disease pathology confirmed $\mathrm{MB}$, the next two consolidation cycles of chemotherapy (i.e., carboplatin, etoposide, and MESNA) resumed. Three months after the completion of treatment, the patient returned to the ED with vomiting, and was found to be bradycardic and hypertensive. An immediate MRI scan revealed significant hydrocephalus secondary to extensive recurrent disease (Figure 2D). external ventricular drain (EVD) was inserted, and the patient was again provided a lower dose of chemotherapy (i.e., temozolamide and irinotecan) for 5 days. As no progression of disease was noted in the interval MRI the child was treated with three fractions of whole-brain radiation (1.8 Gy each) in order to control the tumor while the chemotherapy commenced. The induction chemotherapy was started as per ACNS0334 with high-dose methotrexate to provide intensive re-induction for patients who demonstrate good disease control while on chemotherapy. The re-induction therapy yielded a significant reduction in overall disease burden with the complete resolution of leptomeningeal disease and supratentorial enhancement, only leaving a small nodular enhancement in the posterior fossa. This remarkable response to chemotherapy justified the use of consolidation therapy and autologous stem cell rescue. The consolidation therapy (i.e., triple platinum carboplatin and thiopenta) treated the residual nodular disease, and the patient remained in remission for the next 28.1 months when a routine follow-up MRI identified a left frontal enhancing lesion (Figure 2E). Suspicious of distant metastasis, surgical resection was undertaken and after confirmation of MB histology, the patient was treated with adjuvant CSI (36 Gy) with a further boost to the original and the left frontal metastatic tumor beds (18 Gy). The child has been alive for 7.2 months with stable disease since 
the identification of the distant metastatic recurrence. Interestingly, genetic testing revealed a germline $S U F U$ mutation in the absence of any other genetic or phenotypic abnormalities (e.g., no PTCH-1 mutation, cutaneous cancer lesions, or jaw cysts) previously described as a predisposing mutation in the development of $\mathrm{MB} .{ }^{45}$ Clinical trials investigating the role of smoothened (SMO) inhibitors in relapsed pediatric Shh subgrouped MB exist; however, the early trials failed to show efficacy likely because of their inclusion of children with genetic mutations that are downstream of $S M O$ (e.g., $S U F U) .^{46}$

A similar recent report of effective salvage of two children with desmoplastic MB recurring on the ACNS1221 trial was published by Graham et al. ${ }^{47}$ The first child was 3 years at the time of diagnosis and recurred 3 months post-therapy undergoing a five-drug treatment regimen (i.e., vincristine, cisplatin, etoposide, cyclophosphamide, and high-dose methotrexate) with autologous tandem transplants and proton CSI (23.4 Gy) with a boost to the posterior fossa ( $54 \mathrm{~Gy}$ ) and the spine (45 Gy) for salvage therapy. The second child was a 4-year-old male with Gorlin's syndrome and Trisomy 21 experiencing a local recurrence 9 months after undergoing therapy and was successfully salvaged with three cycles of chemotherapy (i.e., carboplatin and thiopental), and autologous tandem stem cell support without the need for radiation therapy. Although Shh MB is the most common molecular subtype making up the desmoplastic MB histopathological subtype, it is now clear that there are biological differences responsible for the difference in clinical response to therapy that is observed even within the desmoplastic nodular MB subtype. Relevant to our detailed infant desmoplastic nodular MB case, a recent retrospective study of 22 patients from 17 families with a germline $S U F U$ mutation reported a worse 5-year PFS and OS of $42 \%$ and $66 \%$ as compared to Shh MB without $S U F U$ mutations ${ }^{48}$ to explain the unfavorable clinical course experienced by this particular infant. In addition, two recent riskadapted therapy trials, SJC07 and ACNS1221, found that riskadapted therapy did not significantly improve event-free survival prompting the need for a deeper understanding of the biology of pediatric $\mathrm{MB}$ to guide an appropriate individualized upfront therapy. $^{24,49}$

In summary, the overall outcome survival of children experiencing treatment-refractory or recurrent MB is poor. Furthermore, although the salvage strategy for these children appears to have been individualized, further advancement in our understanding of the implications of molecular subgrouping will increasingly facilitate and guide the use of not only upfront molecular therapy but also has the potential to change the landscape of salvage therapy options for treatment-resistant or recurrent pediatric $\mathrm{MB}$.

\section{Strengths and Limitations}

This study had several strengths. Missing data were minimal, given the close monitoring and documentation of the children within the pediatric neurooncology service, in addition to the details added by the members of the PBTSG directly involved in the child's care. In addition, as this is a rare diagnosis, the long duration of participant inclusion reflects the systematic tracking of these children in our institution.

This study is limited by all the factors inherent in conducting a retrospective analysis. The small cohort and heterogeneity of the tumor subtypes of recurrent MB patients limit recommendations with regard to the efficacy of the salvage therapies provided. Although molecular-level data have identified which MB subgroups are at greater risk, prior to 2016 many institutions did not routinely integrate subgrouping into their histopathological diagnosis. In order to facilitate the generation of statements regarding the outcomes of the changes in practice, historical data with sufficient granularity are required. We feel that we have provided this level of detail for our single center cohort and that a multicenter cohort study would have the power to better describe and make recommendations from international experiences treating recurrent pediatric $\mathrm{MB}$ within the molecular era.

\section{Conclusion}

Recurrent pediatric MB in our single center cohort carried a poor prognosis despite the administration of salvage therapy. Although there is standardization of the upfront treatment for these children, we observed great heterogeneity in the treatment of patients experiencing recurrence secondary to either the upfront therapy they had received or tolerability of the therapy proposed. A greater understanding of the biology of recurrent $\mathrm{MB}$ as well as systematic data capture in multicenter studies has the potential to guide salvage therapy.

\section{ACKNOWLEDGements}

The authors would like to acknowledge all the individuals who were vital in the production of the dataset that made the analysis for this study possible.

\section{Disclosures}

None of the authors have any conflicts of interest to disclose.

\section{Author Contributions}

MKS, AF, SKS, MCS, JD, MCA, BY, and OA conceptualized the project. MKS, AS, AM, AMP, and AAA acquired data. MKS and DB coordinated and performed experiments for NanoString subgrouping data analysis in the laboratory of SKS. FF, NA, MKS, AAA, and AF analyzed and interpreted the data. MKS and AAA wrote the manuscript with revisions contributed by AF, MCS, SKS, AAA, and DB. AF and SKS provided guidance related to pediatric neurooncology clinical and pre-clinical, trials respectively. AF and SKS supervised the study. All authors reviewed the results and commented on the manuscript.

\section{REFERENCES}

1. Ramaswamy V, Remke M, Bouffet E, et al. Risk stratification of childhood medulloblastoma in the molecular era: the current consensus. Acta Neuropathol. 2016;131(6):821-31.

2. Polkinghorn WR, Tarbell NJ. Medulloblastoma: tumorigenesis, current clinical paradigm, and efforts to improve risk stratification. Nat Clin Pract Oncol. 2007;4:295-304.

3. Ramaswamy V, Northcott PA, Taylor MD. FISH and chips: the recipe for improved prognostication and outcomes for children with medulloblastoma. Cancer Genet. 2011;204:577-88.

4. Gajjar A, Chintagumpala M, Ashley D, et al. Risk-adapted craniospinal radiotherapy followed by high-dose chemotherapy and stem-cell rescue in children with newly diagnosed medulloblastoma (St Jude Medulloblastoma-96): long-term results from a prospective, multicentre trial. Lancet Oncol. 2006;7:813-20. 
5. Jones DT, Jager N, Kool M, et al. Dissecting the genomic complexity underlying medulloblastoma. Nature. 2012;488:100-5.

6. Bautista F, Fioravantti V, de Rojas T, et al. Medulloblastoma in children and adolescents: a systematic review of contemporary phase I and II clinical trials and biology update. Cancer Med. 2017;6:2606-24.

7. Gilman AL, Jacobsen C, Bunin N, et al. Phase I study of tandem high-dose chemotherapy with autologous peripheral blood stem cell rescue for children with recurrent brain tumors: a Pediatric Blood and MarrowTransplant Consortium study. Pediatr Blood Cancer. 2011;57:506-13.

8. Kramer K, Pandit-Taskar N, Humm JL, et al. A phase II study of radioimmunotherapy with intraventricular (131) I-3F8 for medulloblastoma. Pediatr Blood Cancer. 2018;65:1-10.

9. Akyuz C, Demir HA, Varan A, Yalcin B, Kutluk T, Buyukpamukcu M. Temozolomide in relapsed pediatric brain tumors: 14 cases from a single center. Childs Nerv Syst. 2012;28:111-5.

10. Massimino M, Gandola L, Spreafico F, et al. No salvage using high-dose chemotherapy plus/minus reirradiation for relapsing previously irradiated medulloblastoma. Int J Radiat Oncol Biol Phys. 2009;73:1358-63.

11. De Sio L, Milano GM, Castellano A, et al. Temozolomide in resistant or relapsed pediatric solid tumors. Pediatr Blood Cancer. 2006;47:30-6.

12. Bouffet E, Doz F, Demaille MC, et al. Improving survival in recurrent medulloblastoma: earlier detection, better treatment or still an impasse? Br J Cancer. 1998;77:1321-6.

13. Balter-Seri J, Mor C, Shuper A, Zaizov R, Cohen IJ. Cure of recurrent medulloblastoma: the contribution of surgical resection at relapse. Cancer. 1997;79:1241-7.

14. Chamberlain MC, Kormanik PA. Chronic oral VP-16 for recurrent medulloblastoma. Pediatr Neurol. 1997;17:230-4.

15. Crafts DC, Levin VA, Edwards MS, Pischer TL, Wilson CB. Chemotherapy of recurrent medulloblastoma with combined procarbazine, CCNU, and vincristine. J Neurosurg. 1978;49: 589-92.

16. Baruchel S, Sharp JR, Bartels U, et al. A Canadian paediatric brain tumour consortium (CPBTC) phase II molecularly targeted study of imatinib in recurrent and refractory paediatric central nervous system tumours. Eur J Cancer. 2009;45:2352-9.

17. Beutler D, Avoledo P, Reubi JC, et al. Three-year recurrence-free survival in a patient with recurrent medulloblastoma after resection, high-dose chemotherapy, and intrathecal Yttrium-90-labeled DOTA0-D-Phe1-Tyr3-octreotide radiopeptide brachytherapy. Cancer. 2005;103:869-73.

18. Taylor MD, Northcott PA, Korshunov A, et al. Molecular subgroups of medulloblastoma: the current consensus. Acta Neuropathol. 2012;123:465-72.

19. Cho YJ, Tsherniak A, Tamayo P, et al. Integrative genomic analysis of medulloblastoma identifies a molecular subgroup that drives poor clinical outcome. J Clin Oncol. 2011;29:1424-30.

20. Ramaswamy V, Remke M, Bouffet E, et al. Recurrence patterns across medulloblastoma subgroups: an integrated clinical and molecular analysis. Lancet Oncol. 2013;14:1200-7.

21. ClinicalTrials.gov [Internet]. Reduced craniospinal radiation therapy and chemotherapy in treating younger patients with newly diagnosed WNT-driven medulloblastoma, 18th ed. Bethesda, MD: National Library of Medicine (US); 2018.

22. ClinicalTrials.gov [Internet]. A clinical and molecular risk-directed therapy for newly diagnosed medulloblastoma. Bethseda, MD: National Library of Medicine (US); 2019.

23. ClinicalTrials.gov [Internet]. A study assessing the feasibility of a surgery and chemotherapy-only in children with Wnt positive medulloblastoma. Bethseda, MD: National Library of Medicine; 2018.

24. Schwalbe EC, Lindsey JC, Nakjang S, et al. Novel molecular subgroups for clinical classification and outcome prediction in childhood medulloblastoma: a cohort study. Lancet Oncol. 2017;18:958-71.

25. Robinson GW, Rudneva VA, Buchhalter I, et al. Risk-adapted therapy for young children with medulloblastoma (SJYC07): therapeutic and molecular outcomes from a multicentre, phase 2 trial. Lancet Oncol. 2018;19:768-84.
26. Kool M, Korshunov A, Remke M, et al. Molecular subgroups of medulloblastoma: an international meta-analysis of transcriptome, genetic aberrations, and clinical data of WNT, SHH, Group 3, and Group 4 medulloblastomas. Acta Neuropathol. 2012;123:473-84.

27. Northcott PA, Shih DJ, Remke M, et al. Rapid, reliable, and reproducible molecular sub-grouping of clinical medulloblastoma samples. Acta Neuropathol. 2012;123:615-26.

28. IBM Corp. IBM SPSS statistics for windows, Version 25.0. Armonk, NY: IBM Corp.; Released 2017.

29. Kopecky AS, Khan AJ, Pan W, Drachtman R, Parikh RR. Outcomes and patterns of care in a nationwide cohort of pediatric medulloblastoma: factors affecting proton therapy utilization. Adv Radiat Oncol. 2017;2:588-96.

30. Stensvold E, Krossnes BK, Lundar T, et al. Outcome for children treated for medulloblastoma and supratentorial primitive neuroectodermal tumor (CNS-PNET) - a retrospective analysis spanning 40 years of treatment. Acta Oncol. 2017;56:698-705.

31. Rickert CH, Paulus W. Epidemiology of central nervous system tumors in childhood and adolescence based on the new WHO classification. Childs Nerv Syst. 2001;17:503-11.

32. Koschmann C, Bloom K, Upadhyaya S, Geyer JR, Leary SE. Survival after relapse of medulloblastoma. J Pediatr Hematol Oncol. 2016;38:269-73

33. Dhellemmes P, Demaille MC, Lejeune JP, Baranzelli MC, Combelles G, Torrealba G. Cerebellar medulloblastoma: results of multidisciplinary treatment. Report of 120 cases. Surg Neurol. 1986;25:290-94.

34. Johnston DL, Keene D, Strother D, et al. Survival following tumor recurrence in children with medulloblastoma. J Pediatr Hematol Oncol. 2018;40(3):e159-63.

35. Pietsch T, Schmidt R, Remke M, et al. Prognostic significance of clinical, histopathological, and molecular characteristics of medulloblastomas in the prospective HIT2000 multicenter clinical trial cohort. Acta Neuropathol. 2014;128:137-49.

36. Ellison DW, Kocak M, Dalton J, et al. Definition of disease-risk stratification groups in childhood medulloblastoma using combined clinical, pathologic, and molecular variables. J Clin Oncol. 2011;29:1400-7.

37. Chan MY, Teo WY, Seow WT, Tan AM. Epidemiology, management and treatment outcome of medulloblastoma in Singapore. Ann Acad Med Singapore. 2007;36:314-18.

38. Wetmore C, Herington D, Lin T, Onar-Thomas A, Gajjar A, Merchant TE. Reirradiation of recurrent medulloblastoma: does clinical benefit outweigh risk for toxicity? Cancer. 2014;120: 3731-37.

39. Gottardo NG, Hansford JR, McGlade JP, et al. Medulloblastoma down under 2013: a report from the third annual meeting of the International Medulloblastoma Working Group. Acta Neuropathol. 2014;127:189-201.

40. Louis DN, Perry A, Reifenberger G, et al. The 2016 world health organization classification of tumors of the central nervous system: a summary. Acta Neuropathol. 2016;131:803-20.

41. Wang X, Dubuc AM, Ramaswamy V, et al. Medulloblastoma subgroups remain stable across primary and metastatic compartments. Acta Neuropathol. 2015;129:449-57.

42. Hill RM, Kuijper S, Lindsey JC, et al. Combined MYC and P53 defects emerge at medulloblastoma relapse and define rapidly progressive, therapeutically targetable disease. Cancer Cell. 2015;27:72-84.

43. Morrissy AS, Garzia L, Shih DJ, et al. Divergent clonal selection dominates medulloblastoma at recurrence. Nature. 2016;529:351-57.

44. Friedrich $\mathrm{C}$, von Bueren $\mathrm{AO}$, von Hoff $\mathrm{K}$, et al. Treatment of young children with CNS-primitiveneuroectodermal tumors/pineoblastomas in the prospective multicenter trial HIT 2000 using different chemotherapy regimens and radiotherapy. Neuro Oncol. 2013;15:224-34.

45. Taylor MD, Liu L, Raffel C, et al. Mutations in SUFU predispose to medulloblastoma. Nat Genet. 2002;31:306-10.

46. Kieran MW, Chisholm J, Casanova M, et al. Phase I study of oral sonidegib (LDE225) in pediatric brain and solid tumors and a phase II study in children and adults with relapsed medulloblastoma. Neuro Oncol. 2017;19:1542-52. 
47. Graham RTConley S, Finlay JL, AbdelBack MS. MBCL-06. Successful salvage of desmoplastic nodular medulloblastoma patients treated on ACNS1211. Neurooncol. 2018;20:1.

48. Guerrini-Rousseau L, Dufour C, Varlet P, et al. Germline SUFU mutation carriers and medulloblastoma: clinical characteristics, cancer risk, and prognosis. Neuro Oncol. 2018;20: $1122-32$.
49. Lafay-Cousin L, Bouffet E, Onar-Thomas A, Billups CA, Hawkins C, Eberhart C, Horbinski C, Robinson GW, Strother DR, Heier L, Souweidane MM, Fouladi M, Gajjar A, Children Oncology Group. ACNS1221: a phase II study for the treatment of non metastatic desmoplastic medulloblastoma in children less than 4 years of age - a report of the Children Oncology Group. Journal of Clinical Oncology. 2017;35:10505-5. 